\title{
Mathematical Modeling of the Parabolic Trough Collector Field of the TCP-100 Research Plant
}

\author{
Antonio J. Gallego ${ }^{1}$ Luis J. Yebra ${ }^{2,3}$ Eduardo F. Camacho ${ }^{1} \quad$ Adolfo J. Sánchez $^{1}$ \\ ${ }^{1}$ Dpto. de Ingeniería de Sistemas y Automática, Universidad de Sevilla, Spain, \\ \{antgallen@gmail.com, eduardo@esi.us.es, adolfo.j.sanchez@ieee.org\} \\ ${ }^{2}$ Plataforma Solar de Almería, CIEMAT, Spain, luis. yebraepsa.es \\ ${ }^{3}$ CIESOL, Joint Centre of the University of Almería-CIEMAT, Spain
}

\begin{abstract}
There are two main drawbacks when operating solar energy systems: a) the resulting energy costs are not yet competitive and b) solar energy is not always available when needed. In order to improve the overall solar plants efficiency, advances control techniques play an important role. In order to develop efficient and robust control techniques, the use of accurate mathematical models is crucial. In this paper, the mathematical modeling of the new TCP100 parabolic trough collector (PTC) research facility at the Plataforma Solar de Almería is presented. Some simulations are shown to demonstrate the adequate behavior of the model compared to the facility design conditions.
\end{abstract}

Keywords: solar energy, parabolic trough collector, modeling, simulation

\section{Introduction}

The interest in renewable energy sources such as solar energy, experienced a great impulse after the Big Oil Crisis in the 70s. Driven mainly by economic factors, this interest decreased when oil prices fell. Nowadays, there is a renewed interest in renewable energies spurred by the need of reducing the environmental impact produced by the use of fossil energy systems ((Goswami et al., 2000) (Camacho and Berenguel, 2012)). Solar energy is, by far, the most abundant source of renewable energy (IRENA, 2012).

Many solar electricity production, furnaces, heating and solar cooling systems have been developed in the last decade (Camacho et al., 2012). The main technologies for converting solar energy into electricity are photovoltaic (PV) and concentrated solar thermal (CST). Parabolic trough, solar towers, Fresnel collector and solar dishes are the most used technologies for concentrating solar energy.

As example of the above mentioned, we can mention the following commercial solar plants: The 9 SEGS trough plants (354 MW) which commissioned between 1985 and 1990 in California, are considered to be the first commercial plants. Most of the commercial solar plants have been built and commissioned in the last decade. As examples we can mention the three $50 \mathrm{MW}$ parabolic trough plants Andasol 1,2 and 3 in Guadix (Spain), the solar tower plants of Abengoa PS10 and PS20, Gemasolar solar tower built by Torresol Energy, the three $50 \mathrm{MW}$ Solnova and the two 50 MW Helioenery parabolic trough plants of Abengoa in Spain, and the SOLANA and Mojave Solar parabolic trough plant now operating in Arizona, of 280 MW power production each (Camacho and Gallego, 2013).

One of the first experimental solar trough plants was the solar field ACUREX at the Plataforma Solar de Almería (PSA). It consisted of a field of solar collectors, a heat storage system and an electrical conversion unit (0.5 MW Stal-Laval turbine). This plant has been operating from 1980 to 2013, and many control strategies have been tested there ((Rubio et al., 2006) (Lemos et al., 2000) (Berenguel, 1996) (Gallego et al., 2013)).

There are two main drawbacks when operating solar energy systems: a) the resulting energy costs are not yet competitive and b) solar energy is not always available when needed. Considerable research efforts are being devoted to develop techniques which may help to overcome these drawbacks (Camacho et al., 2011); advanced control is one of those techniques which can help on reduce operating costs and increase solar plants performance $(\mathrm{Ca}-$ macho and Gallego, 2015).

In order to develop control and optimization algorithms for solar energy systems, obtaining an accurate dynamic model is very useful. This paper presents a mathematical model of the new PTC TCP-100 research facility at the PSA, currently under construction.

A considerable research effort has been done in the past concerning the developing of accurate mathematical models describing the dynamics of parabolic trough systems. One of the first work describing the equations which govern the behavior of a parabolic trough loop was done in (Carmona, 1985). For example, in (Yebra et al., 2006), an object oriented modeling and simulation of parabolic trough collectors with modelica is presented. In (Yilmaz and Soylemez, 2014), a complex analysis based on solar, optical and thermal models is developed by using differential and non-linear algebraic correlations. In (JAI and CHALQI, 2013), a mathematical model that describes the heat exchange between the main components of a thermal solar collector in an Integrated Solar Combined Cy- 
cle (ISCC) plant is described. More precise and complex models dealing with modeling of parabolic trough plants with direct vapor generation are described in (Bonilla et al., 2012), (Bonilla, 2013), (yeb, 2005) and (Bonilla et al., 2011).

A PTC solar plant consists mainly of: a collector field, a power conversion system (PCS), a storage system and auxiliary elements such as pumps, pipes and valves ((Duffie and Beckman, 1991), (Camacho et al., 2013)). The solar collector field is formed by PTCs that collect solar radiation and focus it onto a tube in which a heat transfer fluid, usually synthetic oils, circulates. As the oil passes through the metal tube, it is heated up and then used by the PCS to produce electricity by means of a turbine. The storage system is necessary to cover possible mismatches between the solar energy available and the demand. This is one of the advantages of solar thermal energy: the storage of the thermal energy is easier and cheaper than the storage of electrical energy (Herrmann and Kearney, 2002).

The new TCP-100 has new features compared to the ACUREX solar field: the solar tracking system is NorthSouth axis instead of West-East axis of the ACUREX field (Camacho et al., 2007). The collectors and metal tubes are greater and the working temperatures are about 350$380^{\circ} \mathrm{C}$ whereas the normal temperatures of the ACUREX field were about $250-280{ }^{\circ} \mathrm{C}$ (Camacho et al., 1997). A more complete description of the TCP-100 research facility solar field is carried out in section 2 .

The model uses data from data sheets of components and designing conditions from technical documentation of this facility. In particular, parameters related to collectors' size, diameter of the metal tube and the overall optical efficiency. The main characteristics of the heat transfer fluid have been obtained using data from the datasheet provided by the supplier (Dowtherm). Thermal losses will be obtained more precisely when experimental data is available. For simulation purposes, data from the provider of the PTCs is used as a first approximation.

The paper is organized as follows: section 2 provides a complete description of the TCP-100 PTC solar field. Section 3 describes the main assumptions and equations of the mathematical model. Section 4 shows simulations describing the behavior of the model. Finally, section 5 draws to a close with some conclusions.

\section{TCP-100 solar field description}

A new parabolic trough collector facility has been erected at Plataforma Solar de Almería (CIEMAT), in replacement of the so many times referenced ACUREX field that had been operated for more than 30 years. The new facility is named TCP-100 and has been designed mainly to develop automatic control algorithms for parabolic trough solar fields .

The TCP-100 solar field is formed by three loops of parabolic trough collectors (PTC), each of them composed

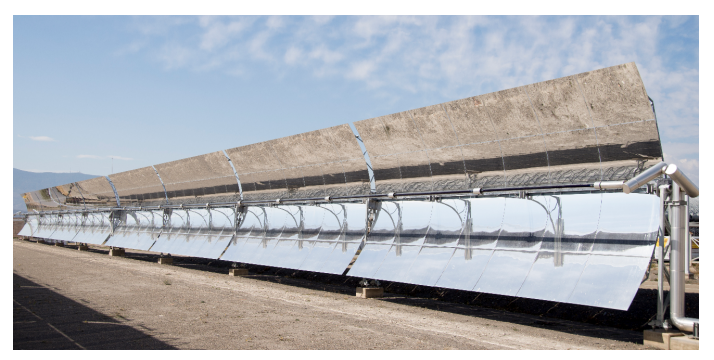

Figure 1. Lateral view of the first TCP-100 PTC in the first loop at Plataforma Solar de Almería (PSA-CIEMAT). It is composed of 8 modules of 12 meters length each.

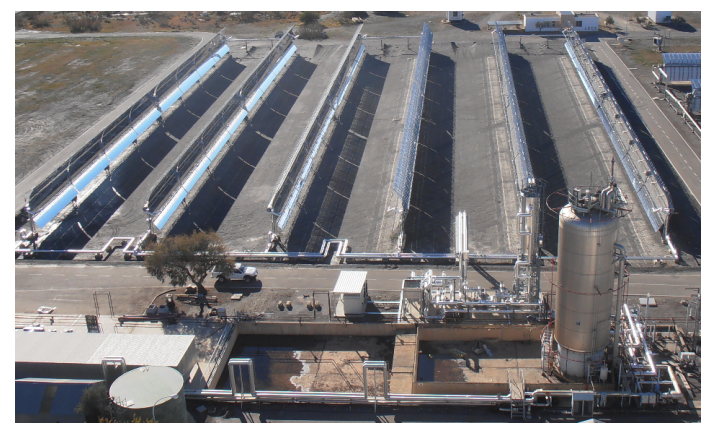

Figure 2. Top view of the TCP-100 field at Plataforma Solar de Almería (PSA-CIEMAT). The three loops are shown, with two PTCs in each of them, numbered from 1 (rightmost) to 6 (leftmost). The first loop is formed by the connected pair 1-2 (right loop), the second loop by 3-4 (center loop) and the third by 5-6 (left loop).

by two PTCs in a North-South orientation. Each of 6 PTCs is $100 \mathrm{~m}$ length, formed by 8 modules in parallel. Fig. 1 shows the first PTC belonging to the first loop.

The PTCs in each loop are connected in the South extreme, and the colder PTC will be always the first in the row, placed at the right part (see Fig. 2).

Remarkable features of the new solar field are those aimed at the experimentation of advanced control techniques, with an important quantity of sensors and actuators with respect to its predecessor ACUREX. These features are summed up:

- Inlet and outlet solar field temperature sensors.

- For each loop, inlet and outlet temperatures are measured. Inside the loop, for each PTC: inlet, outlet and middle point temperatures sensors are available.

- Volumetric flow rate for each loop.

- The aperture of control valves at the input of each loop can be controlled.

The heat transfer fluid is Syltherm 800, suitable for the operating conditions of this new field. Although not treated in this paper, it is worth mentioning that this new solar field is connected to a thermocline storage tank and a cooler cycle through a heat exchanger. The operating 
conditions for a nominal solar radiation of $900 \mathrm{~W} / \mathrm{m}^{2}$ are: $\dot{m}=18.72 \mathrm{~kg} / \mathrm{s}$, inlet and outlet temperatures of $330^{\circ} \mathrm{C}$ and $380^{\circ} \mathrm{C}$ respectively. A schematic diagram of the field is shown in Fig. 3.

\section{Mathematical modeling of TCP-100 solar field}

Each of the TCP-100 loops consists of two eight module PTCs suitably connected in series. Each collector measures $100 \mathrm{~m}$ long and the passive parts joining them (parts where solar radiation does not reach the tube) measures 24 $\mathrm{m}$ long.

This sort of systems can be modeled by using a lumped description (concentrated parameter model) or by a distributed parameter model (Gallego and Camacho, 2012). The approach used here is the distributed parameter model for each loop. The whole solar, composed of the three parallel loops, can be modeled by adding loops in parallel.

The model equations are the same used in the ACUREX solar field developed in (Carmona, 1985) and (Camacho et al., 1997). The model consists of the following system of non-linear partial differential equations (PDE) describing the energy balance:

$$
\begin{gathered}
\rho_{m} C_{m} A_{m} \frac{\partial T_{m}}{\partial t}=I K_{o p t} \cos (\theta) G \\
-H_{l} G\left(T_{m}-T a\right)-L H_{t}\left(T_{m}-T_{f}\right) \\
\rho_{f} C_{f} A_{f} \frac{\partial T_{f}}{\partial t}+\rho_{f} C_{f} q \frac{\partial T_{f}}{\partial x}=L H_{t}\left(T_{m}-T_{f}\right)
\end{gathered}
$$

Where the subindex $m$ refers to metal and $f$ refers to the fluid. The model parameters and their units are shown in Table 1.

In the following, all the parameters needed for the model are described, with the exception of geometric parameters (lengths and areas). The metal density and specific heat correspond to stainless steel tube 321 .

\subsection{Optical and geometric efficiencies}

The optical efficiency, $K_{\text {opt }}$, takes into account elements such as reflectivity, absorptance, interception factor and others. According to the maker, the peak optical efficiency is about 0.76 .

The geometric efficiency, $\cos (\theta)$, is determined by the position of the mirrors with respect to the radiation beam vector. It depends on hourly angle, solar hour, declination, Julianne day, local latitude and collector dimensions (Goswami et al., 2000).

Parabolic trough collectors usually track the sun with one degree of freedom using the E-W axis (as the ACUREX field did) or the N-S axis (Oden and AbuMulaweh, 2013). Solar tracking maintains the plane of
Table 1. Parameters description

\begin{tabular}{ccc}
\hline Symbol & Description & Units \\
\hline $\mathrm{t}$ & Time & $\mathrm{s}$ \\
\hline $\mathrm{x}$ & Space & $\mathrm{m}$ \\
\hline$\rho$ & Density & $\mathrm{Kgm}^{-3}$ \\
\hline $\mathrm{C}$ & Specific heat capacity & $\mathrm{JK}^{-1} \mathrm{~kg}^{-1}$ \\
\hline$A$ & Cross Sectional Area & $\mathrm{m}^{2}$ \\
\hline$T(x, y)$ & Temperature & $\mathrm{K},{ }^{\circ} \mathrm{C}$ \\
\hline$q(t)$ & Oil flow rate & $\mathrm{m}^{3} \mathrm{~s}^{-1}$ \\
\hline$I(t)$ & Solar Radiation & $\mathrm{Wm}^{-2}$ \\
\hline $\cos (\theta)$ & geometric efficiency & $\mathrm{Unitless}$ \\
\hline$K_{o p t}$ & Optical efficiency & $\mathrm{Unitless}$ \\
\hline$G$ & Collector Aperture & $\mathrm{m}$ \\
\hline$T_{a}(t)$ & Ambient Temperature & $\mathrm{K},{ }^{\circ} \mathrm{C}$ \\
\hline$H_{l}$ & Global coefficient & $\mathrm{Wm}^{-2}{ }^{\circ} \mathrm{C}^{-1}$ \\
\multicolumn{3}{c}{ of thermal loss } \\
\hline$H_{t}$ & $\begin{array}{c}\text { Coefficient of heat } \\
\text { transmission metal-fluid }\end{array}$ & $\mathrm{Wm}^{-2}{ }^{\circ} \mathrm{C}^{-1}$ \\
\hline$L$ & Length of pipe line \\
\hline \multicolumn{3}{c}{$\mathrm{m}$} \\
\hline
\end{tabular}

a solar beam so that it is always normal to the collector aperture. Commercial plants use the N-S axis tracking, because it improves greatly the amount of direct solar radiation collected compared to the E-W axis tracking throughout the year (Oden and Abu-Mulaweh, 2013). As stated previously, the TCP-100 solar field uses N-S axis tracking, and the expression for computing the $\cos (\theta)$, is as follows ((Duffie and Beckman, 1991) (Osterholm and Palsson, 2014)).

$$
\cos (\theta)=\sqrt{\cos \left(\theta_{z}\right)^{2}+\cos (\delta)^{2} \sin (\omega)^{2}}
$$

Where $\delta$ is the declination and it can be obtained using the well known Spencer formulas by using equation (4), (Camacho et al., 2012).

$$
\begin{aligned}
\delta & =0.006918-0.399912 \cdot \cos (\omega)+0.070257 \cdot \sin (\omega) \\
& -0.006758 \cdot \cos (2 \cdot \omega)+0.000907 \cdot \sin (2 \cdot \omega) \\
& -0.002697 \cdot \cos (3 \cdot \omega)+0.00148 \cdot \sin (3 \cdot \omega)
\end{aligned}
$$

The variable $\omega$, is the hourly angle, the angular displacement of the sun east or west of the local meridian due to rotation of the earth on its axis at 15 degrees per hour. It can be calculated as follows:

$$
\omega=\left(T_{\text {sun }}-12\right) \cdot 15 \cdot(\Pi / 180)
$$

Where $T_{\text {sun }}$ is the solar hour (Blanco and Santigosa, 2017) which can be computed using the local time as follows (Osterholm and Palsson, 2014):

$$
T_{s}=\text { localhour }+4\left(L_{s t}-L_{l o c}\right)+E_{t}
$$

Where $L_{s t}$ is the standard meridian for the local time zone, $L_{l o c}$ is the longitude of the location in degrees west 


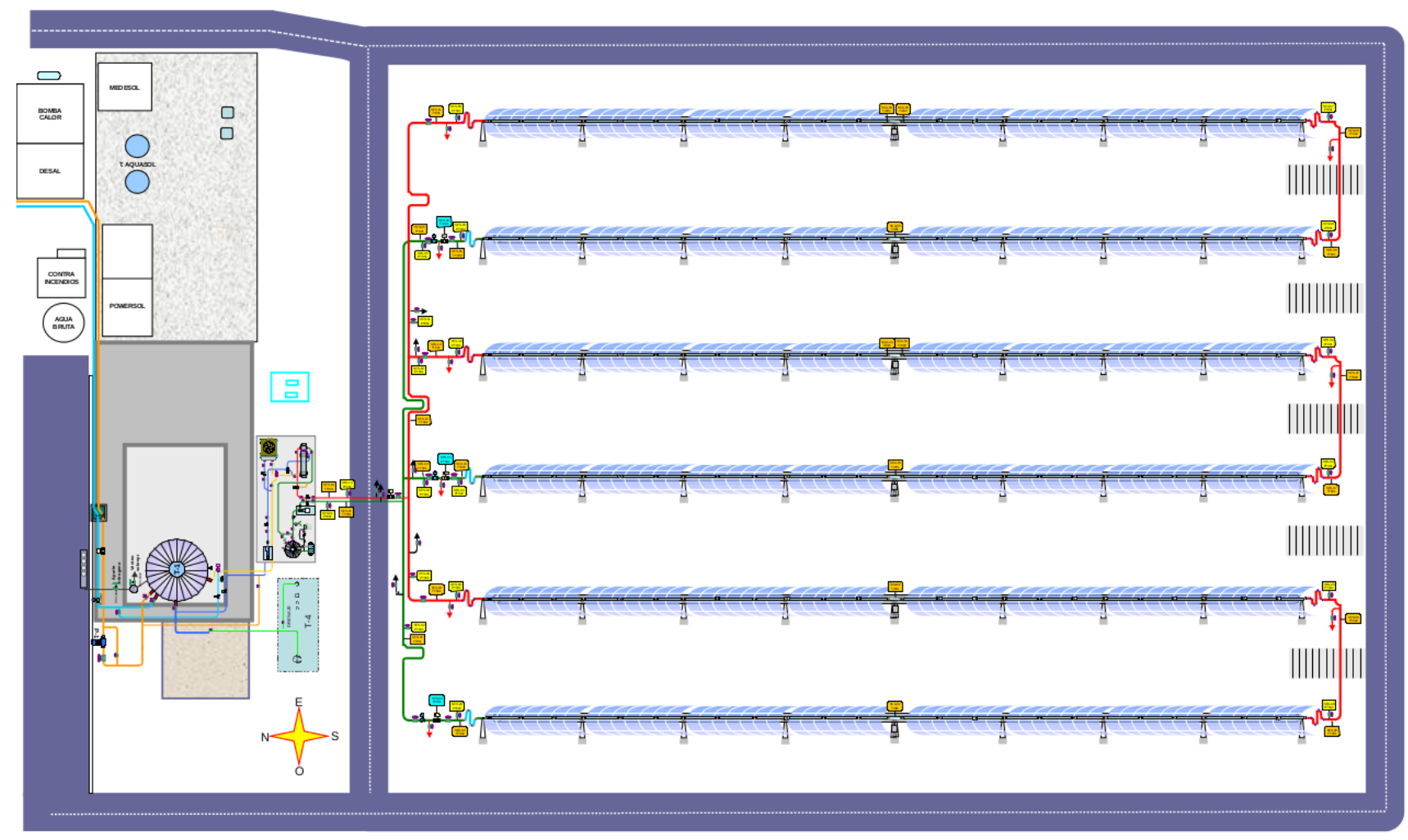

Figure 3. Schematic diagram of the TCP-100 solar field in which the three loops configuration.

and $E_{t}$ is the equation of time (in minutes) which can be obtained using the following equation (6):

$$
\begin{aligned}
E_{t} & =(0.000075+0.001868 \cdot \cos (B) \\
& -0.032077 \cdot \sin (B)-0.014615 \cdot \cos (2 \cdot B) \\
& -0.04089 \cdot \sin (2 \cdot B)) \cdot 229.18
\end{aligned}
$$

With $B$ computed as $B:(2 * \pi / 365) *(J D-1)$, where $J D$ is the Julianne day.

The zenith angle is denoted by $\theta_{z}$, the angle of incidence of beam radiation on a horizontal surface (Duffie and Beckman, 1991). It can be obtained by using the expression (7):

$$
\theta_{z}=\cos (\phi) \cos (\delta) \cos (\omega)+\sin (\phi) \sin (\boldsymbol{\delta})
$$

The variable $\phi$ stands for the Latitude.

\subsection{Characteristics of the heat transfer fluid}

As stated before, the plant uses Syltherm 800 as a heat transfer fluid (HTF). The HTF is a highly stable, longlasting silicone fluid designed for high temperature liquid phase operation. It can operate from $-40{ }^{\circ} \mathrm{C}$ to $400{ }^{\circ} \mathrm{C}$, without degradation.

The density $\rho$, specific heat $C$, and the coefficient of heat transmission have been obtained by data provided in the product data sheet. A polynomial adjustment was performed in order to obtain an expression valid for the entire range of operating temperatures. The expression obtained are:

$$
\begin{gathered}
\rho_{f}=-0.00048098 T_{f}^{2}-0.811 T_{f}+953.65\left(\mathrm{~kg} / \mathrm{m}^{3}\right) \\
C_{f}=0.0000001561 T_{f}^{2}+1.70711 T_{f} \\
+1574.2795\left(\mathrm{~J} /\left(\mathrm{kg}^{\circ} \mathrm{C}\right)\right)
\end{gathered}
$$

The coefficient of heat transmission has two parts: one depends on the temperature of the fluid and the other depends on the oil flow (Camacho et al., 1997). Obtaining the expression of this coefficient involves using complex convection heat transmission formulas (Baerh, 1965).

The expressions are as follows:

$$
\begin{aligned}
H v(T) & =2 \cdot\left(-0.00016213 T_{f}^{3}+1.221 T_{f}^{3}\right. \\
& +115.9983 T_{f}+12659.697 \\
H_{t} & =H v(T) q^{0.8}\left(\mathrm{~W} /\left(\mathrm{m}^{2}{ }^{\circ} \mathrm{C}\right)\right)
\end{aligned}
$$

\subsection{Thermal losses}

The thermal losses coefficient has to be obtained by using experimental data from the actual solar field. However, the field is not operative yet so the experimental data is not available. For simulation purposes, the coefficient of thermal losses has been considered to be similar to that 
used in the ACUREX field, but taking into account that the overall thermal losses for $400{ }^{\circ} \mathrm{C}$ are about $265 \mathrm{~W} / \mathrm{m}^{2}$ as stated in the metal tube data sheet. The coefficient of thermal losses has the following expression:

$$
\begin{aligned}
H_{l} & =0.000357346 \cdot\left(T_{m}-T_{a}\right) \\
& -0.00878632\left(W /\left(m^{2} K\right)\right)
\end{aligned}
$$

When experimental data is available, this coefficient will be adjusted better.

\section{Simulations}

In this section, some simulation results are shown. In these simulations, typical operating values of solar radiation, inlet temperature and oil flow are used. These values are: inlet temperature: $330^{\circ} \mathrm{C}$, outlet temperature: $380^{\circ} \mathrm{C}$ and the nominal mass flow is $18.72 \mathrm{~kg} / \mathrm{s}$ for the whole solar field.

Figure 4 shows a simulation carried out on a summer day (Julianne day: 196). The upper part of figure 4 depicts the field temperatures (inlet and outlet temperatures). The bottom part of figure 4 shows the solar radiation (IDN), the modified solar radiation (mod IDN), namely, the product $I * \cos (\theta)$, and the oil flow multiplied by $100(\mathrm{~kg} / \mathrm{s})$. As can be seen, for the nominal operating conditions, the outlet temperature of the model is very close to that expected in the designing conditions $\left(380^{\circ} \mathrm{C}\right)$.
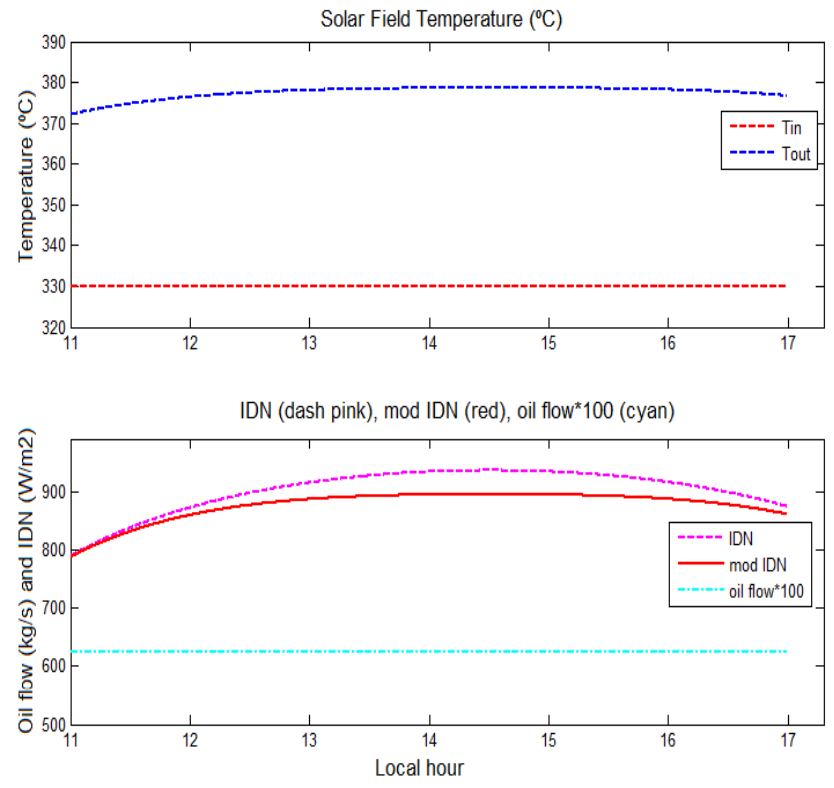

Figure 4. Simulation of a summer day.

Figure 5 plots a simulation performed with data from a winter day (Julianne day: 349). The outlet temperature is substantially lower because the modified solar radiation is much lower. This effect is produced by the $\cos (\theta)$, which is smaller in winter months than summer months. In order to rise the outlet temperature, decreasing the oil flow is indispensable.
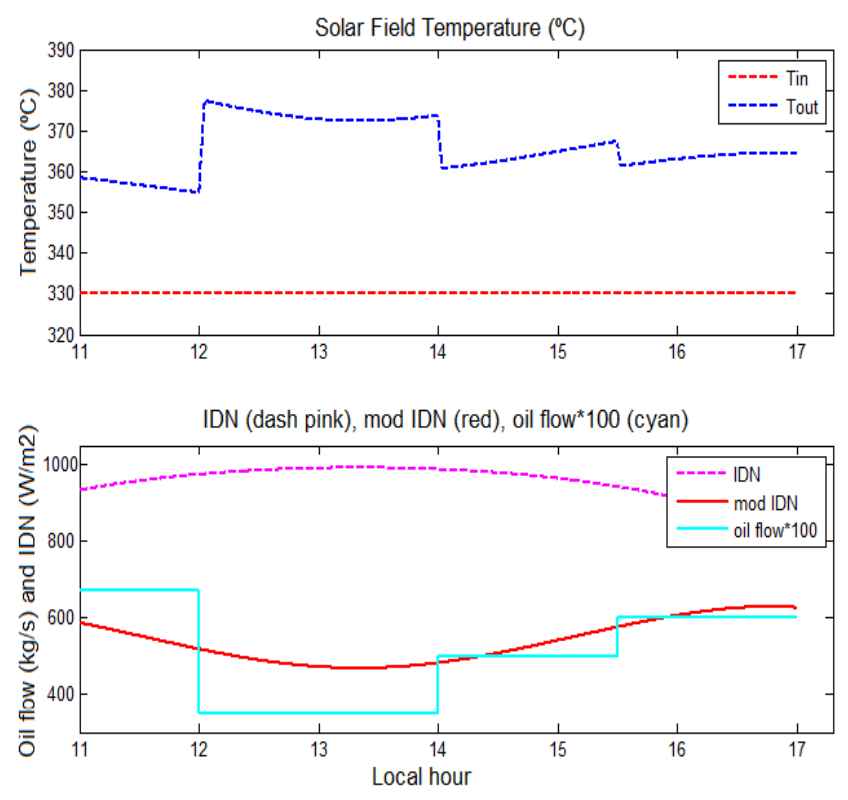

Figure 5. Simulation of a winter day.

The variation of the cosine of the incidence angle is shown in figure 6 for different months. It is shown that the variation of the $\cos (\theta)$ is more pronounced throughout the day in winter days than in summer and spring days, with a deeper valley at the solar noon. In summer days, such as the one belonging to June, the cosine variation is smoother.

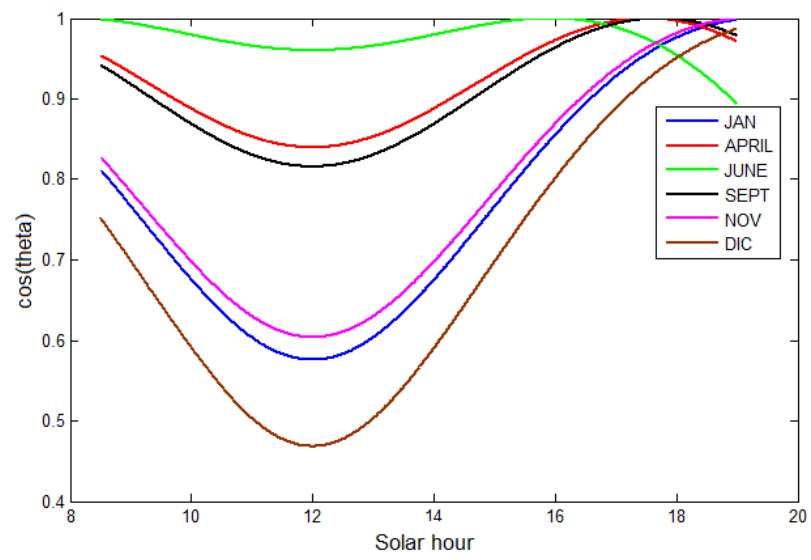

Figure 6. $\cos (\theta)$ variation for different months.

Finally, a day with some transients in solar radiation, produced by scattered clouds, is simulated in figure 7 . The clouds produce that the solar radiation decreased from 14.1 to $14.6 \mathrm{~h}$ approximately, and the solar field temperature decreases correspondingly. Some steps in the oil flow have been produced throughout the day, in order to maintain the outlet temperature around $365^{\circ} \mathrm{C}$, although when the passing clouds affect the solar field, the outlet temper- 
ature decreases significantly as expected.
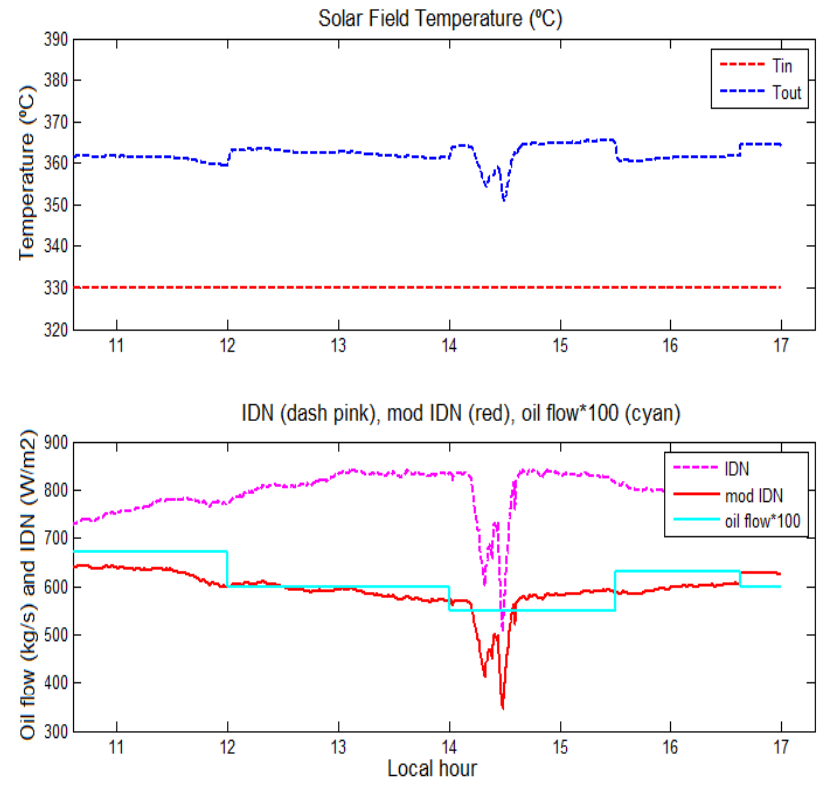

Figure 7. Simulation of a day with scattered clouds.

\section{Conclusions}

In order to develop efficient and robust control techniques, the use of accurate mathematical models of the palnt becomes necessary. A mathematical model of the solar field of the new TCP-100 research facility at the Plataforma Solar de Almería was presented. The simulations of the dynamic model under different operating conditions showed that the model behaved as expected.

As can be seen in figure 4, for the nominal conditions (IDN=900 W/m $\mathrm{m}^{2}, T_{i n}=330$ and the mass flow $=18.72$ $\mathrm{kg} / \mathrm{s}$ ), the model produces a similar outlet temperature to that expected $\left(380^{\circ} \mathrm{C}\right)$.

When experimental data is available and the model adjustment is completed, this will be a very important testbench for simulating advanced control strategies and optimization algorithms.

\section{Acknowledgment}

The authors would like to thank to the CIEMAT Research Centre for supplying useful information to develop the model. We would also thank to the Junta de Andalucía and the European union for partially funding this work under the projects "Gestión óptima de edificios de energía cero" (P11-TEP-8129) and " Dynamic Management of Physically Coupled Systems of Systems" (DYMASOS) (FP7-ICT-ICT-2013.3.4-611281), EU $7^{\text {th }}$ Framework Programme (Theme Energy 2012.2.5.2) under grant agreement 308912 - HYSOL project - Innovative Configuration of a Fully Renewable Hybrid CSP Plant; and the National R+D+i Plan Project DPI2014-56364-C2-2-R of the Spanish Ministry of Economy and Competitiveness and ERDF funds.

\section{References}

Extended moving boundary model for two-phase flows, Prague. Czech Republic, jul 2005.

Hans D. Baerh. Tratado Moderno de Termodinámica. SpringerVerlag, first edition, 1965.

M. Berenguel. to the Control of Distributed Solar Collectors. $\mathrm{PhD}$ thesis, Universidad de Sevilla, 1996.

M. J. Blanco and L. R. Santigosa. Advances in concentrating solar thermal research and Technology. Elselvier, 2017. doi:978-0-08-100517-0.

J. Bonilla. Modeling of Two-phase Flow Evaporators for Parabolic-Trough Solar Thermal Power Plants. Phd thesis, University of Almería, 2013.

J Bonilla, L J Yebra, and S Dormido. A heuristic method to minimise the chattering problem in dynamic mathematical twophase flow models. Mathematical and Computer Modelling, 54(5-6):1549-1560, 2011.

J Bonilla, L J Yebra, S Dormido, and E Zarza. Parabolic-trough solar thermal power plant simulation scheme, multi-objective genetic algorithm calibration and validation. Solar Energy, 86(1):531-540, 2012.

E. F. Camacho and M. Berenguel. Control of solar energy systems. In 8th IFAC Symposium on Advanced Control of Chemical Processes, pages 848-855, 2012.

E. F. Camacho and A. J. Gallego. Optimal operation in solar trough plants: a case study. Solar Energy, 95:106-117, 2013.

E. F. Camacho and A. J. Gallego. Model predictive control in solar trough plants: A review. In 5th IFAC Conference on Nonlinear MPC, September 17-20, Sevilla (Spain), 2015.

E. F. Camacho, F. R Rubio, and M. Berenguel. Advanced control of solar plants. Springer-Verlag, 1997.

E. F. Camacho, T. Samad, M. Garcia-Sanz, and I. Hiskens. Control for renewable energy and smart grids. Technical report, IEEE Control Systems Society, 2011.

E. F. Camacho, M. Berenguel, and A. J. Gallego. Control of thermal solar energy plants. Journal of process control, 2013.

Eduardo F. Camacho, M. Berenguel, Francisco.R. Rubio, and D. Martínez. Control of Solar Energy Systems. SpringerVerlag, 2012.

E.F. Camacho, F.R. Rubio, M. Berenguel, and L. Valenzuela. A survey on control schemes for distributed solar collector fields. part I: Modeling and basic control approaches. Solar Energy, 81:1240-1251, 2007.

Ricardo Carmona. Análisis, Modelado y control de un campo de colectores solares distribuidos con sistema de seguimiento en un eje. $\mathrm{PhD}$ thesis, Universidad de Sevilla, 1985.

J. Duffie and J. Beckman. Solar engineering of thermal processes. Wiley-Interscience, 2nd edition, 1991a. 
A. J. Gallego and E. F. Camacho. Adaptative state-space model predictive control of a parabolic-trough field. Control Engineering Practice, 20 (9):904-911, 2012.

A. J. Gallego, F. Fele, E. F. Camacho, and L. J. Yebra. Observerbased model predictive control of a solar trough plant. Solar Energy, 97:426-435, 2013.

D. Yogi Goswami, F. Kreith, and J. F. Kreider. Principles of Solar Engineering. 2nd edition, 2000.

Ulf Herrmann and David W. Kearney. Survey of thermal energy storage for parabolic trough power plants. Journal of Solar Energy Engineering, 124:145-152, May 2002.

IRENA. Renewable energy technologies: Cost analysis series: Concentrating solar power. Technical report, International Renewable Energy Agency, 2012.

M.C. EL JAI and F.Z. CHALQI. A modified model for parabolic trough solar receiver. American Journal of Engineering Research, 02 (05):200-211, 2013.

J.M. Lemos, L.M. Rato, and E. Mosca. Integrating predictive and switching control: Basic concepts and an experimental case study. In F. Allgower and A. Zheng, editors, Nonlinear Model Predictive Control, number 1, pages 181-190. 2000.

S. D. Oden and H. I. Abu-Mulaweh. Design and development of an educational solar tracking parabolic trough collector system. Global Journal of Engineering Education, 15 (1):21-27, 2013.

R. Osterholm and J. Palsson. Dynamic modelling of a parabolic trough solar power plant. In Proceedings of the 10th International Modelica Conference, Lund, Sweden, March 10-12 2014.

F.R. Rubio, E. F. Camacho, and R. Carmona. Control de campos de colectores solares. RIAI Revista Iberoamericana de Automática e Informática Industrial, 3:26-45, 2006.

L.J. Yebra, M. Berenguel, E. Zarza, and S. Dormido. Object oriented modelling and simulation of parabolic trough collectors with modelica. In 5th MathMod Conference 2006, volume 14, pages 361-375, Vienna University of Technology. Austria, feb 2006. Taylor \& Francis. doi:10.1080/13873950701847199.

I. H. Yilmaz and M. S. Soylemez. Thermo-mathematical modeling of parabolic trough collector. Energy Conversion and Management, 88:768-784, 2014. 